\title{
Retrospective Analysis of Metabolic Syndrome: Prevalence and Distribution in Executive Population in Urban Pakistan
}

\author{
Niloufer Sultan Ali, ${ }^{1}$ Ali Khan Khuwaja, ${ }^{1}$ Adnan-ur-Rahman, ${ }^{2}$ and Kashmira Nanji ${ }^{1}$ \\ ${ }^{1}$ Department of Family Medicine, Aga Khan University Hospital, Aga Khan University, Stadium Road, \\ P.O. Box 3500, Karachi 74800, Pakistan \\ 2 Jinnah Postgraduate Medical College, Jinnah Postgraduate Medical Centre (JPMC), Rafiquee Shaheed Road, \\ P.O. Box 3937, Karachi 74800, Pakistan \\ Correspondence should be addressed to Kashmira Nanji, kashmira.nanji@aku.edu \\ Received 30 March 2012; Revised 26 July 2012; Accepted 29 July 2012 \\ Academic Editor: P. Van Royen
}

Copyright (๑) 2012 Niloufer Sultan Ali et al. This is an open access article distributed under the Creative Commons Attribution License, which permits unrestricted use, distribution, and reproduction in any medium, provided the original work is properly cited.

\begin{abstract}
Background. Metabolic Syndrome (MetS) is a major public health concern. Objective. The aim of this study was to estimate the frequency of MetS, its components, and factors associated with MetS amongst apparently healthy individuals in Pakistan. Methods. A retrospective cross-sectional study was conducted at the executive Clinics of Aga Khan Hospital, Pakistan. Medical records of patients aged $\geq 18$ years visiting the clinics from July 2011 to December 2011 were consecutively reviewed. Records in which either MetS components data or $10 \%$ of overall data was missing were excluded. A total of 1329 participants' records was included in final analysis. Data was analyzed using SPSS version 19 and multivariable logistic regression was used to identify the factors associated with MetS. Results. A total of 847 (63.7\%) participants had MetS; mean age of the participants were $47.6 \pm 11.6$ years. About $70.4 \%$ were males and $29.6 \%$ were females. Approximately $70 \%$ of participants had BMI $\geq 25 \mathrm{~kg} / \mathrm{m}^{2}$. MetS was associated with male gender $(\mathrm{AOR}=2.1 ; 95 \%$ C.I: $1.6-3.2)$ and history of diabetes among parents ( $\mathrm{AOR}=3.0$; 95\% C.I: 1.6-6.0). Conclusion. This study shows that a large proportion of population has MetS and is overweight or obese. This requires urgent interventions on part of health care providers' especially family physicians. Educating masses about life style factors can make a difference. Further researches on this issue are warranted.
\end{abstract}

\section{Introduction}

Globally, Metabolic Syndrome (MetS) has become a public health concern and is a major cause of morbidity and mortality. Many studies have provided strong evidence for the association of MetS with acute coronary syndrome [14]. In health care services the value of MetS derives largely from its potential to reduce the risk of cardiovascular disease in the general population by treating the disease [5].

There has been much a debate on the definition of MetS. However, recent definition of MetS given by American heart association and the National heart, Lung and Blood Institute (AHA/NHLBI) in 2005 declared that a clinical diagnosis of MetS can be established if any three of the following factors are present, elevated triglyceride level (TG): elevated waist circumference, decreased HDL-cholesterol (HDL) level, elevated fasting glucose, and elevated blood pressure [6].

The estimated prevalence of MetS in general population is between 17 and 25\% [7]. Various studies have demonstrated that the major causes leading to MetS are insulin resistance, obesity, and genetic predisposition [8]. Several cross-sectional studies have established that overweight and obesity are clearly associated with risk factor components that make up MetS [9].

A recent study from Sweden has shown that presence of MetS can give essential prognostic information of cardiovascular mortality if the current status of risk factors is known in an individual [2]. Recently questions have been raised about the role of MetS as a separate entity, associated with 
a greater risk of development of cardiovascular disease. IndoAsian population has highest risk of developing coronary artery disease in the world, thus it is not surprising that it has become a common cause of death in this subcontinent $[10,11]$. With increasing urbanization the risk of developing MetS and its associated risk factors like ischemic heart disease is only likely to show an upward trend.

The incidence of Type 2 Diabetes Mellitus (T2DM) has been increasing in the last decades and is projected to rise from 171 million in 2000 to 366 million in 2030 [12]. In Pakistan, about $10 \%$ of adult population is having diabetes, ranking sixth with an increasing trend [13]. It is projected that if the situation persists, by the year 2030 Pakistan will rank the 4th in the world for the burden of diabetes [13]. Several population studies have indicated that metabolic syndrome is a risk factor for the development of T2DM $[8,14$, 15].

Studies have shown that unlike European countries the risk of developing cardiovascular disease and its associated risk factors like hypertension, dyslipidemia is nearly equivalent among men and women in Asian countries [16]. A very often occurring point in the prevalence of MetS is that it shows age dependence whereas its prevalence has been shown to increase with increasing age [17]. Among South Asians cardiovascular risk factors are seen at a younger age and the reason for this is still unclear [18].

Recently some controversies were raised by Kahn regarding the definition of MetS which implies that the factors included in the definition of MetS should have greater predictive power than all other combinations [19]. Nonetheless, there is no obvious evidence which shows this.

Family physicians/general practitioners mainly focuse on holistic and integrated care with health promotion and disease prevention: the core of their practice. Usually they are the first contact with the patients, hence, awareness regarding MetS and the individual risk of each component is vital so that individualized treatment/prevention strategies can be implemented. Therefore, this study was designed to estimate the frequency of MetS, its components, factors associated, and clustering of different components of MetS amongst apparently healthy individuals in Pakistan.

\section{Material and Methods}

A retrospective cross sectional study was done at the executive Clinics of the Aga Khan University Hospital Karachi, Pakistan (AKUH). The Aga Khan University is a not-forprofit, tertiary care hospital. Medical records of all patients aged 18 years onwards who came for their routine annual physical checkups over a period of six months at executive clinics of AKUH from July 2011 to December 2011 were consecutively reviewed. Patients for which either MetS components (BMI, FBS, HDL, BP, TRIG) data or $10 \%$ of overall data was missing were excluded from the study. A total of 1500 medical records were reviewed. 171 patients' data were incomplete and therefore were excluded and remaining 1329 patients' records were included in final analysis.

The routine examination at the executive clinics, AKUH, includes a detailed physical examination comprising height, weight, blood pressure, thorough general and physical examination along with complete blood picture, erythrocyte sedimentation rate, fasting blood sugar, lipid profile, liver function tests, creatinine, uric acid, chest X-ray, and ECG.

A structured questionnaire was formulated to extract the information. These questionnaires were filled by a medical graduate specifically trained for the task and it was composed of two sections. Section A included questions on demographic detail of the participants (age, gender). Section B dealt with the risk factors of MetS including BMI, blood pressure, fasting blood sugar, triglycerides, and HDL. This section also included questions on family history of CVD among parents, sibling, and children. The study was reviewed and approved by the Family Medicine's Departmental Research Committee of The Aga Khan University Hospital, Karachi, Pakistan.

According to the new International Diabetes Federation definition, for a person to be defined as having the metabolic syndrome they must have the following [20].

Central Obesity. Males $\geq 90 \mathrm{~cm}$ and females $\geq 80 \mathrm{~cm}$ (based on Asian Indian, Malay \& Chinese population). The new International Diabetes Federation definition suggests that If BMI is $>30 \mathrm{~kg} / \mathrm{m}^{2}$, central obesity can be assumed and waist circumference does not need to be measured. In this study we used Asian cutoff for obesity that is, $\geq 25 \mathrm{~kg} / \mathrm{m}^{2}$.

Also they must have any two of the following four factors:

(1) raised triglycerides: $\geq 150 \mathrm{mg} / \mathrm{dL}(1.69 \mathrm{mmol} / \mathrm{L})$;

(2) reduced HDL cholesterol: $<40 \mathrm{mg} / \mathrm{dL}(1.04 \mathrm{mmol} / \mathrm{L})$ in men and $<50 \mathrm{mg} / \mathrm{dL}(1.29 \mathrm{mmol} / \mathrm{L})$ in women;

(3) raised blood pressure: $\geq 130 / 85 \mathrm{~mm} \mathrm{Hg}$;

(4) raised plasma fasting glucose: $\geq 100 \mathrm{mg} / \mathrm{dL} \quad(\geq 6.1$ $\mathrm{mmol} / \mathrm{L})$.

Statistical analysis was carried out using SPSS software (Statistical Package for the Social Sciences, version 17). Proportions were reported for all the variables such as age, gender, and components of MetS. Univariate and multivariate logistic regression was done to identify the factors associated with MetS. The results are reported in form of odds ratio and $95 \%$ confidence intervals. A $P$ value of $<0.05$ was considered statistically significant throughout the study.

\section{Results}

A total of 1329 patients' records were included in the final analysis and for missing data we averaged estimates of the variables to give a single mean estimate. The medical record indicates that out of the total patients $936(70.5 \%)$ were males and 393 (29.5) were females. The mean age of the patients was $47.6 \pm 11.6$ years.

Table 1(a) depicts the age- and gender-specific percentages of individual component of MetS. A total of 847 participants had MetS, thus showing a prevalence of $63.7 \%$. Almost $70 \%$ of the patients had BMI over 25. As compared to females, males had higher prevalence of BMI over 
TABLE 1: Age and gender specific prevalence of individual components of MetS among 1329 participants.

(a) Total population

\begin{tabular}{|c|c|c|c|c|}
\hline Parameter & $\begin{array}{l}\text { Total population } \\
\qquad N=1329\end{array}$ & $\begin{array}{l}\text { Men only } \\
N=936\end{array}$ & $\begin{array}{l}\text { Women only } \\
\qquad N=393\end{array}$ & $P$ value \\
\hline Age* $^{*}$ & $47.6( \pm 11.6)^{*}$ & $936(70.5)$ & $393(29.5)$ & 0.13 \\
\hline$\%$ BMI: $\geq 25 \mathrm{~kg} / \mathrm{m}^{2}$ & $934(70.3)$ & $654(70.0)$ & $280(30.0)$ & 0.61 \\
\hline$\%$ raised triglycerides & $532(41.6)$ & $399(75.0)$ & $133(25.0)$ & 0.02 \\
\hline$\%$ reduced HDL cholesterol & $715(58.7)$ & $478(66.9)$ & $237(33.1)$ & $<0.001$ \\
\hline$\%$ raised blood pressure & 729 (54.9) & $536(73.5)$ & $193(26.5)$ & 0.006 \\
\hline$\%$ raised plasma fasting glucose & $834(63.4)$ & $624(74.8)$ & $210(25.2)$ & $<0.001$ \\
\hline
\end{tabular}

${ }^{*}$ Mean (standard deviation), $N$ : number (percentage).

$P$-value: difference in males and females, significance at $<0.05$.

BMI: $\geq 25 \mathrm{~kg} / \mathrm{m}^{2}$.

Raised triglycerides: $\geq 150 \mathrm{mg} / \mathrm{dL}(1.69 \mathrm{mmol} / \mathrm{L})$.

Reduced HDL cholesterol: $<40 \mathrm{mg} / \mathrm{dL}(1.04 \mathrm{mmol} / \mathrm{L})$ in $\mathrm{men},<50 \mathrm{mg} / \mathrm{dL}(1.29 \mathrm{mmol} / \mathrm{L})$ in women.

Raised blood pressure: $\geq 130 / 85 \mathrm{~mm} \mathrm{Hg}$.

Raised plasma fasting glucose: $\geq 100 \mathrm{mg} / \mathrm{dL}(\geq 6.1 \mathrm{mmol} / \mathrm{L})$.

(b) Age less than 40 years

\begin{tabular}{|c|c|c|c|c|}
\hline Parameter & $\begin{array}{l}\text { Total population } \\
\qquad N(\%)\end{array}$ & $\begin{array}{c}\text { Men only } \\
N(\%)\end{array}$ & $\begin{array}{l}\text { Women only } \\
\qquad N(\%)\end{array}$ & $P$-value \\
\hline Age $<40$ years & $323(24.3)$ & $222(68.7)$ & $101(31.3)$ & 0.44 \\
\hline $\mathrm{BMI} \geq 25 \mathrm{~kg} / \mathrm{m}^{2}$ & $218(67.5)$ & $157(72.0)$ & $61(28.0)$ & 0.04 \\
\hline Raised triglycerides & $109(34.8)$ & $131(75.2)$ & $73(24.8)$ & 0.03 \\
\hline Reduced HDL cholesterol & $195(63.7)$ & $128(65.6)$ & $67(34.4)$ & 0.04 \\
\hline Raised blood pressure & $127(39.3)$ & $105(82.7)$ & $22(17.3)$ & $<0.001$ \\
\hline Raised plasma fasting glucose & $135(42.2)$ & $108(80.0)$ & $27(20.0)$ & $<0.001$ \\
\hline
\end{tabular}

$N$ : number (percentage).

$P$-value: difference in males and females, significance at $<0.05$.

(c) Age more than 40 years

\begin{tabular}{|c|c|c|c|c|}
\hline Parameter & $\begin{array}{c}\text { Total population } \\
\qquad N(\%)\end{array}$ & $\begin{array}{c}\text { Men only } \\
N(\%)\end{array}$ & $\begin{array}{c}\text { Women only } \\
N(\%)\end{array}$ & $P$-value \\
\hline Age $>40$ years & $1006(75.7)$ & $714(71.0)$ & $292(29.0)$ & 0.44 \\
\hline$\%$ BMI: $\geq 25 \mathrm{~kg} / \mathrm{m}^{2}$ & $716(71.2)$ & $497(69.4)$ & $219(30.6)$ & 0.05 \\
\hline \% Raised triglycerides & $423(43.8)$ & $317(74.9)$ & $106(25.1)$ & 0.02 \\
\hline \% Reduced HDL cholesterol & $520(57.0)$ & $350(67.3)$ & $170(32.7)$ & $<0.001$ \\
\hline$\%$ Raised blood pressure & $602(59.8)$ & $431(71.6)$ & $171(28.4)$ & 0.59 \\
\hline$\%$ Raised plasma fasting glucose & $699(70.2)$ & $516(73.8)$ & $183(26.2)$ & 0.002 \\
\hline
\end{tabular}

$N$ : number (percentage).

$P$-value: difference in males and females, significance at $<0.05$.

$25(70 \% \mathrm{v} / \mathrm{s} 30 \%)$. Over two-thirds of the patients had raised plasma blood glucose. However, one-third $(33 \%)$ of the total female population had reduced HDL levels.

Table 1(b) shows the age- (less than 40 years) and genderspecific component of MetS. In all, $23.3 \%$ of the populations were aged less than 40 years, with $68.1 \%$ males and the rest were females. About $34.8 \%$ of the patients had raised triglyceride levels, while $65.6 \%$ of the males and $34.4 \%$ of the females less than 40 years had reduced HDL levels $(P=0.04)$. The $P$-values were significant for all components, suggesting there was significant difference among males and females with respect to the components of MetS.

Table $1(\mathrm{c})$, presents the age and sex specific distribution of components of MetS, who are more than 40 years old.
About three fourth of the total patient population were more than 40 years of age. Majority of the patients $(71.7 \%)$ had BMI $>25$ and all the results were statistically significant at $5 \%$ significance level $(P<0.05)$ except raised blood pressure $(P=0.59)$.

The association of demographic and family factors with MetS is presented in Table 2. The odds of having MetS were 2 times higher among males (AOR: 2.1 ; 95\% C.I: $1.6-3.2$ ) as compared to females. Those patients who had past history of diabetes were 5 times at risk of developing MetS as compared to others when adjusted for other variables in the model (AOR: 5.3; 95\% CI: 1.0-74) and was highly significant $(P<$ 0.001 ). About $60 \%$ of the patients who had MetS had family history of diabetes among parents, while about two-third 
TABLE 2: Univariate and multivariable logistic regression analysis of factors associated with MetS.

\begin{tabular}{|c|c|c|c|c|c|}
\hline Variable & $\begin{array}{c}\text { MS present } \\
N=847 \\
(63.7)\end{array}$ & $\begin{array}{c}\text { MS absent } \\
N=482 \\
(36.3)\end{array}$ & $\begin{array}{l}\text { Unadjusted odds } \\
\text { ratio ( } 95 \% \text { C.I })\end{array}$ & $\begin{array}{l}\text { Adjusted odds } \\
\text { ratio }(95 \% \mathrm{CI})\end{array}$ & $P$ value \\
\hline \multicolumn{6}{|l|}{ Gender } \\
\hline Female & $227(57.8)$ & $166(42.2)$ & 1 & 1 & \multirow{2}{*}{0.003} \\
\hline Male & $620(66.2)$ & $316(33.8)$ & $1.4(1.1-1.8)$ & $2.1(1.6-3.2)$ & \\
\hline \multicolumn{6}{|c|}{ Educational status $€$} \\
\hline University level & $242(28.6)$ & $97(20.2)$ & 1 & 1 & \multirow{3}{*}{0.01} \\
\hline Secondary level & $255(30.0)$ & $179(37)$ & $1.5(1.3-1.8)$ & $2.2(1.5-3.2)$ & \\
\hline Primary level & $350(41.4)$ & $206(42.8)$ & $2.0(1.4-2.8)$ & $3.0(2.4-3.8)$ & \\
\hline \multicolumn{6}{|c|}{ Past history of diabetes } \\
\hline No & $483(57)$ & $294(61)$ & 1 & 1 & \multirow{2}{*}{$<0.001$} \\
\hline Yes & $364(43)$ & $188(39)$ & $3.3(2.20-4.6)$ & $5.3(1.0-74)$ & \\
\hline \multicolumn{6}{|c|}{ Family history of diabetes of parents } \\
\hline No & $338(40.0)$ & $146(30.4)$ & 1 & 1 & \multirow{2}{*}{0.04} \\
\hline Yes & $509(60.0)$ & $336(69.6)$ & $2.3(1.2-4.0)$ & $3.0(1.6-6.0)$ & \\
\hline \multicolumn{6}{|c|}{ Family history of diabetes of sibling } \\
\hline No & $295(34.8)$ & $145(30)$ & 1 & 1 & \multirow{2}{*}{0.03} \\
\hline Yes & $552(65.1)$ & $337(70)$ & $1.4(1.2-1.6)$ & $2.4(1.0-4.8)$ & \\
\hline \multicolumn{6}{|c|}{ Family history of CVD of parents } \\
\hline No & $232(27.5)$ & $366(76.1)$ & 1 & 1 & \multirow{2}{*}{ NS } \\
\hline Yes & $615(72.5)$ & $116(23.9)$ & $1.5(0.5-4.5)$ & $6.9(0.8-8.4)$ & \\
\hline \multicolumn{6}{|c|}{ Family history of CVD of sibling } \\
\hline No & $289(34.2)$ & $184(38.2)$ & 1 & 1 & \multirow{2}{*}{ NS } \\
\hline Yes & $558(65.8)$ & $298(61.8)$ & $4.4(0.8-6.4)$ & $6.0(4.7-7.8)$ & \\
\hline
\end{tabular}

95\% CI: 95\% confidence interval, NS: not significant at $P$ value $<0.05$. Educational Status $€$ : university level (14 years or more), secondary level (6-12 years of education), and primary level (1-5 years of education).

MetS patients had family history of diabetes among siblings (AOR: 3.0; 95\% C.I: 1.6-6.0). The other variables which were statistically insignificant at the multivariate regression were family history of CVD among parents and siblings. About $41 \%$ of the patients who had MetS; had 5 or less years of education and the maximum risk was also observed amongst them (AOR: 3.0; 95\% CI: 2.4-3.8).

The pattern of appearance of MetS components among study participants is depicted in Figure 1 . Only $2.6 \%$ of the participants had no risk factor of MetS, while around $11 \%$ of the participants had 5 or more risk factors. Almost 30\% of the participants had 3 risk factors, whereas, $10 \%$ and $21 \%$ of the participants had 1 and 2 risk factors of MetS respectively.

\section{Discussion}

In this study the prevalence of MetS was found to be $63.7 \%$ among the study participants. The results also highlight that BMI over 25 was the most common $(70.3 \%)$ risk factor present among the cases of MetS. This prevalence of MetS is almost twice as high as in the United States as determined in NHANES data [21]. The major reason for this variation can be the fact that in this study we used BMI $\geq 25 \mathrm{~kg} / \mathrm{m}^{2}$ for diagnosis of MetS and due to this a large proportion of participants were included in the definition of MetS. According to IDF, a BMI cutoff of $\geq 30 \mathrm{~kg} / \mathrm{m}^{2}$ can be used for diagnosing MetS [20], nonetheless in Asian population the cutoff for obesity is $\geq 25 \mathrm{~kg} / \mathrm{m}^{2}$, which was used in this study [22]. However, Asian cutoff of BMI for diagnosis of diabetes and CVD is $\geq 23 \mathrm{~kg} / \mathrm{m}^{2}$ due to the difference in adiposity, as Asians tend to have more central obesity than other populations [22]. Though analysis was also performed at BMI cutoff of $\geq 23 \mathrm{~kg} / \mathrm{m}^{2}$ to observe any change in the prevalence of MetS. Nonetheless there was no difference in prevalence of MetS when the cutoff $\geq 23 \mathrm{~kg} / \mathrm{m}^{2}$ was used.

The prevalence of MetS in Pakistan is showing an upward trend [23]. The results of this study cannot be compared to other studies conducted in Pakistan. As these studies have shown contrasting prevalence of MetS ranging from as low as $20 \%$ and as high as $85 \%$ [23-25], there were differences in definitions of MetS and population selection, that is, participants with comorbidities such as T2DM. A study by Mohsin et al. found a high prevalence of $85 \%$ and was conducted on type 2 diabetics [25]. Results from other populations reported the prevalence to be between 70 to $80 \%$ among Caucasians with T2DM [26] and 75.6\% among 


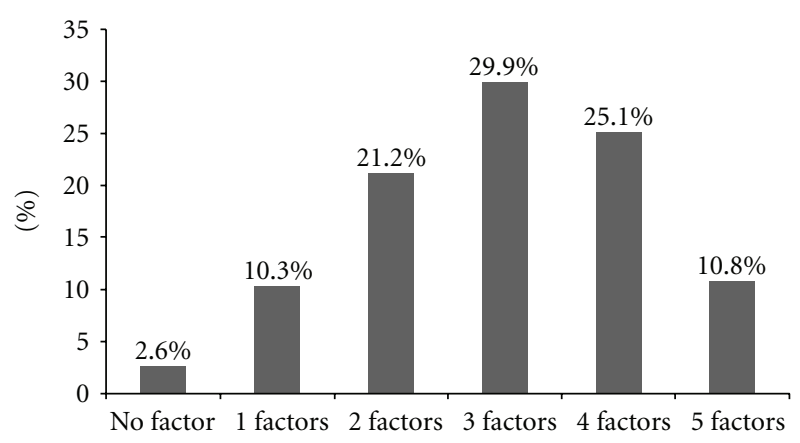

Figure 1: Pattern of appearance of MetS components among study participants.

Chinese diabetics [27]. This high prevalence $63.4 \%$ of MetS that we observe in the study can be attributed to $43 \%$ of the patients who had past history of T2DM.

It is well reported that the risk factors which are most frequently present in MetS cases include obesity, coronary heart disease, sedentary lifestyle, aging, and lipodystrophy $[28,29]$.

Various studies reveal that the components which make up MetS vary in the rates in which they occur in different populations $[18,19]$. The Seychelles study conducted on 1255 participants reported that adiposity and high blood pressure are most common occurring components of MetS [30]. However, in the present study BMI in 70\% and high fasting blood glucose in $62 \%$ of the study participants were the most prevalent components. This is not surprising as it has been evident that central obesity precedes the appearance of other MetS components and it also plays a crucial role in the development of MetS [31]. Moreover, in Asian population central obesity is found to be more common [22]. An analysis of the National Health Survey of Pakistan revealed that $25 \%$ of our population is obese [22]. Latest researches have now shown that although obesity is an intriguing factor of MetS there are some phenotypes which alters this definition [32]. Despite having BMI exceeding $30 \mathrm{~kg} / \mathrm{m}^{2}$, individuals are relatively insulin sensitive and lack most of the metabolic abnormalities typical of obese individuals [32]. These individuals' phenotypes separate obesity from its usual metabolic consequences and demands more focus on clustering of the risk factors.

The incidence of T2DM worldwide is rising exponentially due to increase in sedentary life style leading to central abdominal obesity [22]. T2DM is one of the most common chronic diseases worldwide and the fourth or fifth leading cause of death in the developed world $[12,13]$. There is ample data to suggest that presence of MetS intensifies the risk of developing T2DM to manyfold $[14,15]$. "Clustering" of metabolic abnormalities (hypertension, hyperinsulinemia hypertriglycemia, hyperglycemia) that occur in the individual appears to confer a substantial additional risk for developing future T2DM, which would add to the 230 million people worldwide who already have diabetes $[12,18]$.

A prospective cohort study conducted on 2,924 patients found that the presence of MetS in patients was associated with a four- to sixfold increased risk of future T2DM [33]. Another study suggested that people with metabolic syndrome have a fivefold greater risk of developing T2DM [34]. In this study we found that about $62.8 \%$ of the total population had impaired fasting glucose, which is an important indicator to predict T2DM. These results are also consistent with a study conducted in Africa which concluded that a large proportion of patients with impaired glucose tolerance had MetS [30].

Studies have presented contrasting results on the use of TG/HDL ratio (dyslipidemia) as a marker for MetS [35]. A study conducted in California on 258 diabetic participants considered TG/HDL ratio as a strong marker of MetS. However, another study on African Americans showed complementary result on the use of TG/HDL ratio as an ineffective marker of insulin resistance $[35,36]$. Our study results are congruent with the previous study on African Americans [36]; we have observed low HDL level in 53\% and an elevated triglyceride level in only $40 \%$. This finding can also be the result of ethnic differences.

The present study reveals that MetS was more common among the male participants (66\%); this finding is contrary to previous studies which showed a higher prevalence of MetS among women [37]. This change in results can be due to the recent urbanization in our society [22], which has affected males more; as majority of males are now driving cars that have replaced pedal walking, working on desk-based office jobs, sitting at computer for long hours and changing in dietary pattern, that is, junk food, all these have put people at risk of more obesity than it could ever be imagined.

Despite the close association between MetS components and high blood pressure levels, it is difficult to describe the contribution of each component in the increment of blood pressure levels. Previously, it has been shown that a high prevalence of MetS is present among essential hypertensives than in general population [38]. In Asia Pacific the most contributing component towards development of MetS was hypertension [39], but this is contrary to our findings; in our study $54 \%$ of the study participants with uncontrolled blood pressure had MetS.

The PAMELA study had recently provided us further data on association of MetS with cardiovascular risk factors [40]. Although we have described each component of MetS as an independent risk factor for development of cardiovascular disease, the highest prevalence observed was with a combination of three risk factors, with an extremely low proportion without any risk factor, that is, $2.6 \%$. Increasing research over contribution of MetS components in the development of cardiovascular disease is being done [41].

Several epidemiological studies and clinical medicine had recognized that family history is a risk factor for many chronic diseases such as T2DM $[42,43]$. Recognition of family history is not only useful in predicting genetic susceptibility of an individual to a disease but is also advantageous for early detection and preventive strategies. Likewise, family history of diabetes is not only a risk factor but is also associated with risk-reducing behaviors [42]. It is well known that T2DM has a strong genetic component and most patients of T2DM have a first-degree relative with diabetes 
[44]. Many studies have provided evidence for association of MetS with family history of diabetes [42-44]. A nationally representative sample of US adults had shown a significant and positive association between family history of diabetes and MetS components [44]. Another recent cross-sectional study conducted by Das et al. in Kolkata, India, on 448 adults has found that those individuals whose parents and siblings had history of T2DM had more prevalence of MetS components as compared to their counterparts $(P<0.001)$ [45]. This study results are also congruent to other studies as those patients whose parents and/or their siblings had history of diabetes were two (AOR: 2.4, 95\% CI: 1.0-4.8) and three times (AOR: 3.0, 95\% CI: 1.6-6.0) at risk of developing MetS, respectively.

Epidemiological studies have considered educational status as a surrogate measure for socioeconomic status [46, 47]. However, it can roughly predict the job opportunities and future socioeconomic status. In addition, it plays a vital role in shaping the attitudes and behavior of individual towards health. Studies had found inverse and strong relationship between educational status and presence of MetS [45-47]. There is obviously no direct association of education with MetS but it may influence the life style changes. A study conducted on 300 women also concluded that the risk of MetS increases among less educated individuals [48]. This is also consistent with the current study results as the risk of MetS is 3 times higher in those who have primarylevel education, as compared to those with higher level of education.

The association of education and socioeconomic status with MetS was most observed among females as they are more subjective to socioeconomic inequalities in our continent $[46,49]$. Nevertheless, the health of women in Pakistan is compromised, since they are not empowered to take their own decisions and are not allowed to go outside their homes without accompanying male member of the house [49]. This leaves them more exposed to sedentary life style and obesity, precursors of MetS [49]. We do not have the actual income data of the participants so we cannot comment on the direction of association between socioeconomic status and MetS. However we can assume that the population coming to the study setting would be affluent (through cost of examination) and their health behavior and attitude are different from the general population, another reason for high prevalence of MetS.

4.1. Role of Family Physician. With the rise of epidemics of type 2 diabetes and CVD worldwide it is important for family physicians to identify those individuals with metabolic syndrome early, so that lifestyle interventions and treatment may prevent the development of diabetes and/or cardiovascular disease. These can be done in three ways; educational strategies: through information about MetS, its components, risk factors that are found to be common in Pakistani population; preventive strategies: screening for high risk groups such as family history of diabetes, obesity, and so forth, promoting life style changes to avoid obesity; pharmacotherapy:
Aggressive pharmacologic management of risk factors in preventing complications of T2DM.

4.2. Limitations. This study has some limitations. Since this was a retrospective study so temporal associations cannot be ruled out. Moreover, we did not have information on waist circumference of the patients so we could not observe the association of MetS and abdominal obesity (common in Pakistani population) in our study. The data has been extracted from a hospital so extrapolation of the results to the general population must be done with caution. The data was gathered from executive clinics so their health-seeking behavior and patterns can be different from those of the general population. The missing data in the study were handled through mean imputation which can distort the association between the factors.

\section{Conclusion}

This study from one of the largest cosmopolitan cities of the world highlights a high prevalence of MetS and its components. The presence of such factors among apparently healthy individuals is a cause of concern and requires the need for urgent interventions in order to prevent and control MetS and its associated risk factors such as T2DM and CVD. These interventions should be based on the integrated lifestyle approach, keeping in mind the socioeconomic status of the population. Health care providers should provide awareness regarding MetS risk factors and its prevention to patients and their families. Awareness sessions should also be held to educate the masses through media. Nevertheless, further research is required to explore this vital issue in detail and to develop and test the interventions.

\section{Conflict of Interests}

The authors declare that they have no conflict of interests.

\section{Acknowledgments}

The authors are thankful to all the nursing and administrative staffs of the clinic.

\section{References}

[1] T. Kasai, K. Miyauchi, T. Kurata et al., "Prognostic value of the metabolic syndrome for long-term outcomes in patients undergoing percutaneous coronary intervention," Circulation Journal, vol. 70, no. 12, pp. 1531-1537, 2006.

[2] J. Sundström, U. Risérus, L. Byberg, B. Zethelius, H. Lithell, and L. Lind, "Clinical value of the metabolic syndrome for long term prediction of total and cardiovascular mortality: prospective, population based cohort study," BMJ, vol. 332, no. 7546, pp. 878-881, 2006.

[3] A. A. Rizvi, "Inflammation markers as mediators of vasculoendothelial dysfunction and atherosclerosis in the metabolic syndrome and type 2 diabetes," Chinese Medical Journal, vol. 120, no. 21, pp. 1918-1924, 2007. 
[4] Z. Cao, Y. J. Zhou, Y. X. Zhao, Y. Y. Liu, Y. H. Guo, and W. J. Cheng, "Rosiglitazone could improve clinical outcomes after coronary stent implantation in nondiabetic patients with metabolic syndrome," Chinese Medical Journal, vol. 119, no. 14, pp. 1171-1175, 2006.

[5] J. B. Buse, H. N. Ginsberg, G. L. Bakris et al., "Primary prevention of cardiovascular diseases in people with diabetes mellitus: a scientific statement from the American Heart Association and the American Diabetes Association," Diabetes Care, vol. 30, no. 1, pp. 162-172, 2007.

[6] S. M. Grundy, J. I. Cleeman, S. R. Daniels et al., "Diagnosis and management of the metabolic syndrome An American Heart Association/National Heart, Lung, and Blood Institute scientific statement," Current Opinion in Cardiology, vol. 21, no. 1, pp. 1-6, 2006.

[7] F. Alsaraj, J. H. McDermott, T. Cawood et al., "Prevalence of the metabolic syndrome in patients with diabetes mellitus," Irish Journal of Medical Science, vol. 178, no. 3, pp. 309-313, 2009.

[8] B. Balkau, J. E. Deanfield, J. P. Després et al., "International day for the evaluation of abdominal obesity (IDEA): a study of waist circumference, cardiovascular disease, and diabetes mellitus in 168000 primary care patients in 63 countries," Circulation, vol. 116, no. 17, pp. 1942-1951, 2007.

[9] Y. W. Park, S. Zhu, L. Palaniappan, S. Heshka, M. R. Carnethon, and S. B. Heymsfield, "The metabolic syndrome: prevalence and associated risk factor findings in the US population from the Third National Health and Nutrition Examination Survey, 1988-1994," Archives of Internal Medicine, vol. 163, no. 4, pp. 427-436, 2003.

[10] M. Gupta, N. Singh, and S. Verma, "South Asians and cardiovascular risk: what clinicians should know," Circulation, vol. 113, no. 25, pp. e924-e929, 2006.

[11] P. Joshi, S. Islam, P. Pais et al., "Risk factors for early myocardial infarction in South Asians compared with individuals in other countries," JAMA, vol. 297, no. 3, pp. 286-294, 2007.

[12] W. Rathmann, G. Giani, S. H. Wild et al., "Global prevalence of diabetes: estimates for the year 2000 and projections for 2030," Diabetes Care, vol. 27, no. 10, pp. 2568-2569, 2004.

[13] S. Nishtar, S. Shera, G. Raffique, K. B. Mohamud, and A. Ahmed, "Diabetes prevention and control: national Action Plan for NCD Prevention, Control and Health Promotion in Pakistan," Journal of the Pakistan Medical Association, vol. 54, no. 12, pp. S-26-S-30, 2004.

[14] R. L. Hanson, G. Imperatore, P. H. Bennett, and W. C. Knowler, "Components of the "metabolic syndrome" and incidence of type 2 diabetes," Diabetes, vol. 51, no. 10, pp. 3120-3127, 2002.

[15] P. W. F. Wilson, R. B. D’Agostino, H. Parise, L. Sullivan, and J. B. Meigs, "Metabolic syndrome as a precursor of cardiovascular disease and type 2 diabetes mellitus," Circulation, vol. 112, no. 20, pp. 3066-3072, 2005.

[16] T. H. Jafar, "Women in Pakistan have a greater burden of clinical cardiovascular risk factors than men," International Journal of Cardiology, vol. 106, no. 3, pp. 348-354, 2006.

[17] L. Fezeu, B. Balkau, A. P. Kengne, E. Sobngwi, and J. C. Mbanya, "Metabolic syndrome in a sub-Saharan African setting: central obesity may be the key determinant," Atherosclerosis, vol. 193, no. 1, pp. 70-76, 2007.

[18] V. Tikhonoff and E. Casiglia, "Metabolic syndrome: nothing more than a constellation?" European Heart Journal, vol. 28, no. 7, pp. 780-781, 2007.

[19] R. Kahn, "The metabolic syndrome (Emperor) wears no clothes," Diabetes Care, vol. 29, no. 7, pp. 1693-1696, 2006.
[20] K. G. M. M. Alberti, P. Zimmet, and J. Shaw, "Metabolic syndrome-a new world-wide definition. A consensus statement from the International Diabetes Federation," Diabetic Medicine, vol. 23, no. 5, pp. 469-480, 2006.

[21] R. B. Ervin, "Prevalence of metabolic syndrome among adults 20 years of age and over, by sex, age, race and ethnicity, and body mass index: United States, 2003-2006," National Health Statistics Reports, no. 13, pp. 1-7, 2009.

[22] T. H. Jafar, N. Chaturvedi, and G. Pappas, "Prevalence of overweight and obesity and their association with hypertension and diabetes mellitus in an Indo-Asian population," CMAJ, vol. 175, no. 9, pp. 1071-1077, 2006.

[23] M. Z. Iqbal Hydrie, A. S. Shera, A. Fawwad, A. Basit, and A. Hussain, "Prevalence of metabolic syndrome in urban Pakistan (Karachi): comparison of newly proposed international diabetes federation and modified adult treatment panel III criteria," Metabolic Syndrome and Related Disorders, vol. 7, no. 2, pp. 119-124, 2009.

[24] A. Basit and A. S. Shera, "Prevalence of metabolic syndrome in Pakistan," Metabolic Syndrome and Related Disorders, vol. 6, no. 3, pp. 171-175, 2008.

[25] A. Mohsin, J. Zafar, Y. B. Nisar et al., "Frequency of the metabolic syndrome in adult type 2 diabetics presenting to Pakistan Institute of Medical Sciences," Journal of the Pakistan Medical Association, vol. 57, no. 5, pp. 235-238, 2007.

[26] H. F. Abdul-Rahim, A. Husseini, E. Bjertness, R. Giacaman, N. H. Gordon, and J. Jervell, "The metabolic syndrome in the West Bank population: an urban-rural comparison," Diabetes Care, vol. 24, no. 2, pp. 275-279, 2001.

[27] G. N. Thomas, S. Y. Ho, E. D. Janus, K. S. L. Lam, A. J. Hedley, and T. H. Lam, "The US National Cholesterol Education Programme Adult Treatment Panel III (NCEP ATP III) prevalence of the metabolic syndrome in a Chinese population," Diabetes Research and Clinical Practice, vol. 67, no. 3, pp. 251-257, 2005.

[28] C. Lara-Castro, Y. Fu, B. H. Chung, and W. T. Garvey, "Adiponectin and the metabolic syndrome: mechanisms mediating risk for metabolic and cardiovascular disease," Current Opinion in Lipidology, vol. 18, no. 3, pp. 263-270, 2007.

[29] O. Renaldi, B. Pramono, H. Sinorita, L. B. Purnomo, R. H. Asdie, and A. H. Asdie, "Hypoadiponectinemia: a risk factor for metabolic syndrome," Acta Medica Indonesiana, vol. 41, no. 1, pp. 20-24, 2009.

[30] S. A. Isezuo and E. Ezunu, "Demographic and clinical correlates of metabolic syndrome in native African type-2 diabetic patients," Journal of the National Medical Association, vol. 97, no. 4, pp. 557-563, 2005.

[31] P. Zimmet, G. K. M. M. Alberti, F. Kaufman et al., "The metabolic syndrome in children and adolescents-an IDF consensus report," Pediatric Diabetes, vol. 8, no. 5, pp. 299306, 2007.

[32] C. L. Jennings, E. V. Lambert, M. Collins, Y. Joffe, N. S. Levitt, and J. H. Goedecke, "Determinants of insulin-resistant phenotypes in normal-weight and obese black african women," Obesity, vol. 16, no. 7, pp. 1602-1609, 2008.

[33] A. M. J. Wassink, Y. Van Der Graaf, S. S. Soedamah-Muthu, W. Spiering, and F. L. J. Visseren, "Metabolic syndrome and incidence of type 2 diabetes in patients with manifest vascular disease," Diabetes and Vascular Disease Research, vol. 5, no. 2, pp. 114-122, 2008.

[34] K. G. M. M. Alberti, R. H. Eckel, S. M. Grundy et al., "Harmonizing the metabolic syndrome: a joint interim statement of the international diabetes federation task force on epidemiology and prevention; National heart, lung, and blood 
institute; American heart association; World heart federation; International atherosclerosis society; And international association for the study of obesity," Circulation, vol. 120, no. 16, pp. 1640-1645, 2009.

[35] S. J. Kim-Dorner, P. A. Deuster, S. A. Zeno, A. T. Remaley, and M. Poth, "Should triglycerides and the triglycerides to highdensity lipoprotein cholesterol ratio be used as surrogates for insulin resistance?" Metabolism, vol. 59, no. 2, pp. 299-304, 2010.

[36] A. E. Sumner, K. B. Finley, D. J. Genovese, M. H. Criqui, and R. C. Boston, "Fasting triglyceride and the triglyceride-HDL cholesterol ratio are not markers of insulin resistance in African Americans," Archives of Internal Medicine, vol. 165, no. 12, pp. 1395-1400, 2005.

[37] A. E. Sumner, J. Zhou, A. Doumatey et al., "Low HDL-cholesterol with normal triglyceride levels is the most common lipid pattern in West Africans and African Americans with Metabolic Syndrome: implications for cardiovascular disease prevention," CVD Prevention and Control, vol. 5, no. 3, pp. 7580, 2010.

[38] G. Mancia, G. Parati, C. Borghi et al., "Hypertension prevalence, awareness, control and association with metabolic abnormalities in the San Marino population: the SMOOTH study," Journal of Hypertension, vol. 24, no. 5, pp. 837-843, 2006.

[39] A. L. Martiniuk, C. M. Lee, C. M. M. Lawes et al., "Hypertension: its prevalence and population-attributable fraction for mortality from cardiovascular disease in the Asia-Pacific region," Journal of Hypertension, vol. 25, no. 1, pp. 73-79, 2007.

[40] G. Mancia, M. Bombelli, G. Corrao et al., "Metabolic syndrome in the Pressioni Arteriose Monitorate E Loro Associazioni (PAMELA) study: daily life blood pressure, cardiac damage, and prognosis," Hypertension, vol. 49, no. 1, pp. 40 47, 2007.

[41] E. Oda, "The metabolic syndrome (emperor) wears no clothes," Diabetes Care, vol. 29, no. 11, pp. 2566-2567, 2006.

[42] J. K. Y. Li, M. C. Y. Ng, W. Y. So et al., "Phenotypic and genetic clustering of diabetes and metabolic syndrome in Chinese families with type 2 diabetes mellitus," Diabetes/Metabolism Research and Reviews, vol. 22, no. 1, pp. 46-52, 2006.

[43] A. Masoom, I. Pims, and S. Tareen, "Metabolic syndrome in non-diabetic first degree relatives of type 2 diabetic patients," Annals of Pakistan Institute of Medical Sciences, vol. 7, no. 2, pp. 65-71, 2010.

[44] A. Ghosh, T. Liu, M. J. Khoury, and R. Valdez, "Family history of diabetes and prevalence of the metabolic syndrome in U.S. adults without diabetes: 6-year results from the national health and nutrition examination survey (1999-2004)," Public Health Genomics, vol. 13, no. 6, pp. 353-359, 2010.

[45] M. Das, S. Pal, and A. Ghosh, "Family history of type 2 diabetes and prevalence of metabolic syndrome in adult Asian Indians," Journal of Cardiovascular Disease Research, vol. 3, no. 2, pp. 104-108, 2012.

[46] J. Lidfeldt, P. Nyberg, C. Nerbrand, G. Samsioe, B. Scherstén, and C. D. Agardh, "Socio-demographic and psychosocial factors are associated with features of the metabolic syndrome. The Women's Health in the Lund Area (WHILA) study," Diabetes, Obesity and Metabolism, vol. 5, no. 2, pp. 106-112, 2003.

[47] M. H. Kim, M. K. Kim, B. Y. Choi, and Y. J. Shin, "Educational disparities in the metabolic syndrome in a rapidly changing society-the case of South Korea," International Journal of Epidemiology, vol. 34, no. 6, pp. 1266-1273, 2005.

[48] S. P. Wamala, J. Lynch, M. Horsten, M. A. Mittleman, K. Schenck-Gustafsson, and K. Orth-Gomer, "Education and the metabolic syndrome in women," Diabetes Care, vol. 22, no. 12, pp. 1999-2003, 1999.

[49] A. K. Khuwaja and M. M. Kadir, "Gender differences and clustering pattern of behavioural risk factors for chronic non-communicable diseases: community-based study from a developing country," Chronic Illness, vol. 6, no. 3, pp. 163-170, 2010. 


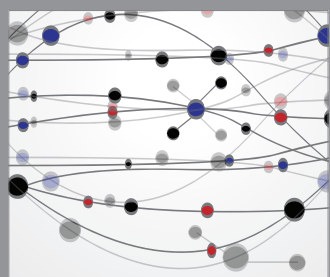

The Scientific World Journal
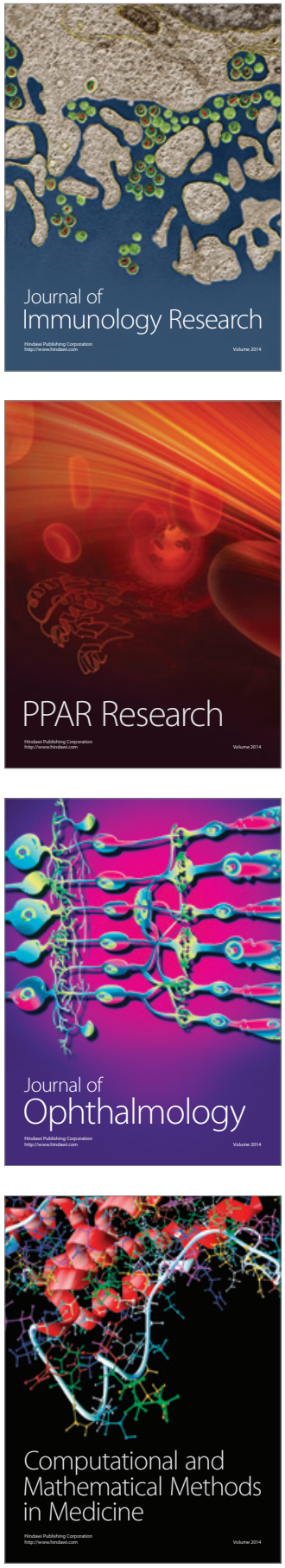

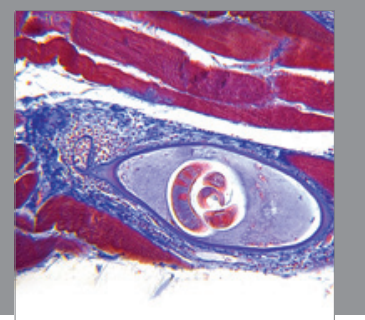

Gastroenterology

Research and Practice
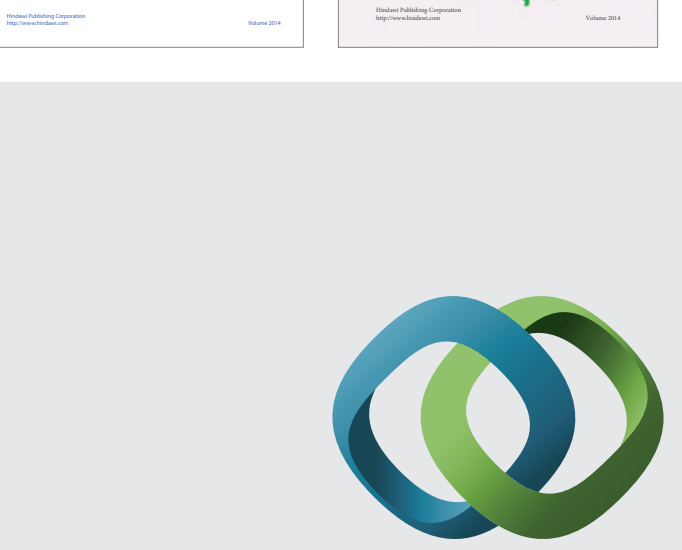

\section{Hindawi}

Submit your manuscripts at

http://www.hindawi.com
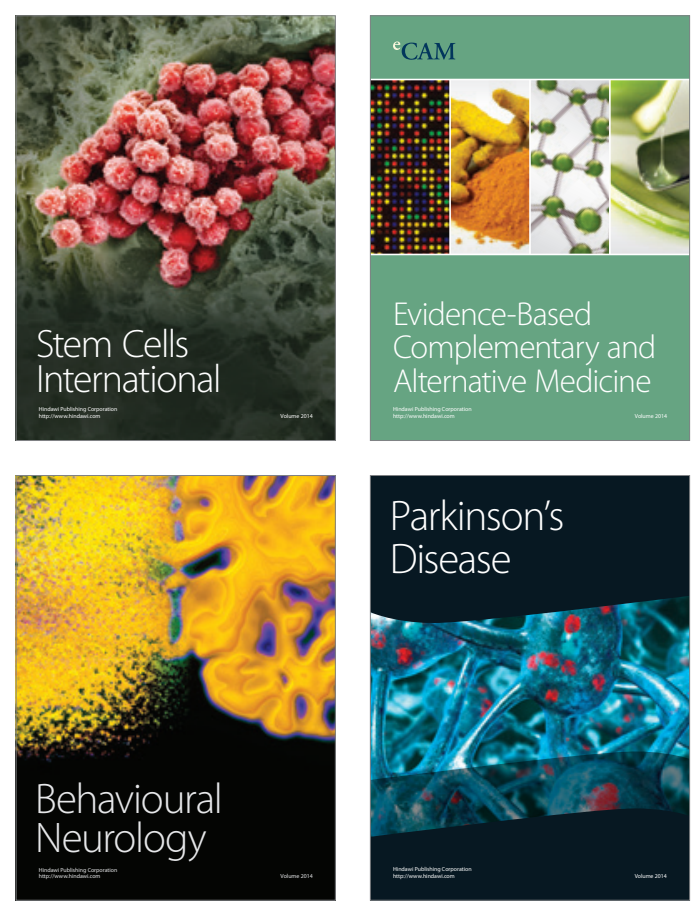

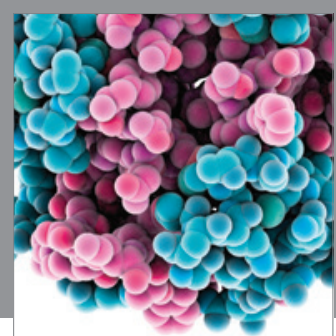

Journal of
Diabetes Research

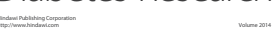

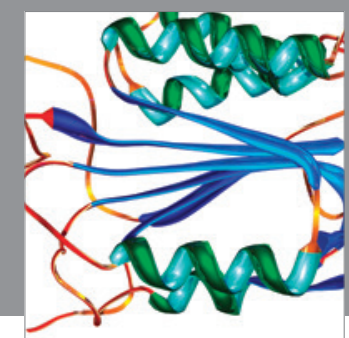

Disease Markers
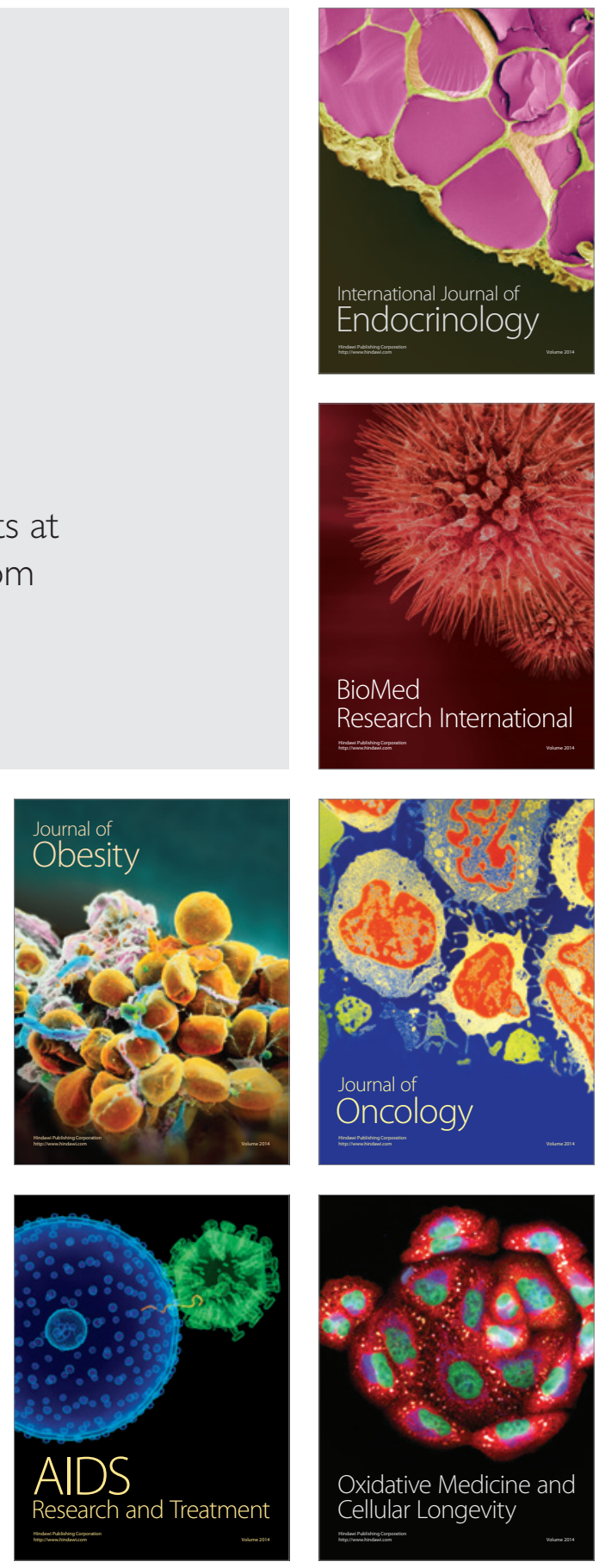